\title{
Personal characteristics of wives of law enforcement officers as predictors of the formation of the psychological climate in the family system
}

\author{
Julia Kreneva ${ }^{1}$, Elena Suroedova ${ }^{2, *}$, Olga Korzhova $^{2}$, Tatiana Ozerova ${ }^{1}$ \\ ${ }^{1}$ Southern Federal University, Academy of Psychology and Pedagogy, 344006, Rostov-on-Don, Russia \\ ${ }^{2}$ Don State Technical University, 344000, Rostov-on-Don, Russia
}

\begin{abstract}
The article deals with the psychological climate in the families of law enforcement officers, which largely depends on the personal characteristics of their wives. Since it is a woman who is historically the "home keeper" and one of her family functions is to provide and maintain an optimal psychological atmosphere in the family, the topic of the article is particularly interesting and relevant. The empirical sample was made up of 205 women who are the spouses of law enforcement officers. The following methods were applied: "Individual typological questionnaire (ITQ) L.N. Sobchik, "Questionnaire of the level of subjective control" (LSC) of the E. G. Bekhterev's research Institute, "Analysis of family anxiety" (AFA) Eidemiller and V. Justitskis, "Understanding, emotional attraction, authority" (UEA) by A. N. Volkova, "Marriage satisfaction Questionnaire" (MSQ) by V. V. Stolin, T. A. Romanova and G. P. Butenko, statistical linear method of regression analysis. The influence of personal characteristics and locus of control of the wives of law enforcement officers on these components of the psychological climate of the family is established. The results were analyzed and conclusions were drawn about the quality of influence of personal characteristics of the wives of law enforcement officers on the components of the psychological climate in their families.
\end{abstract}

\section{Introduction}

The specifics of the activities of law enforcement officers are characterized by the variety and complexity of the tasks set, including participation in activities related to the implementation of responsible assignments and activities in extreme conditions. Research by domestic and foreign scientists is devoted to the study of various negative consequences of the professional activities of law enforcement officers, such as emotional burnout of law enforcement officers [1], psychological maladaptation and depression [2], as well as promotion of a healthy lifestyle, prevention of substance abuse and suicide prevention [3].

Recently, foreign and domestic sources describe the factors of satisfaction/dissatisfaction with professional activity, staff turnover in the organizational context. By studying the

\footnotetext{
* Corresponding author: suroedova@mail.ru
} 
individual and organizational effects of professional quality of life on public safety employees, Miller A. and Unruh L. [4] found that perceived organizational support is linked to job satisfaction and a sense of security, which in turn determines employee turnover in the organization. The works of Butt M. R., Mahmood A. et al. [5] established the influence of perceived organizational policies on the performance of tasks by employees, transmitted only through affective organizational commitment. Rodionova V. I., Shvachkina L. A., Ponomaryov P. A., Vodenko K. V. study the role of public administration in the development of social and labor relations [6].

Wolfe S.E., Rojek J., Manjarrez V. M., Rojek, A. found that employees faced with uncertainty paid more attention to fair treatment of their superiors than their colleagues considering how satisfied they were with their work. The results showed that both general workplace uncertainty and uncertainty caused by recently perceived negative advertising weakened the relationship between organizational fairness and job satisfaction [7]. Researchers Schuck A. M., Rabe-Hemp, C. E. found that the level of official salary affects staff turnover in law enforcement agencies: high wages are largely associated with lower rates of voluntary and involuntary staff turnover; other economic incentives and participation in a defined benefit pension plan were associated with voluntary resignation but not with dismissal [8].

Russian psychology offers measures of psychological support for Ministry of National Affairs employees at the initial stages of professionalization [9], a model approach in the professional psychological selection of law enforcement officers [10], measures to prevent conflict situations and formation of anti-corruption stability in law enforcement officers [11].

Often, performing these tasks entails emotional exhaustion, physical and emotional fatigue [12], which, in turn, can negatively affect the family and household sphere. For example, Burch T. [13] shows that overtime indirectly changes the interaction between work and family, negatively affecting satisfaction within the family system and can change the actual structure and composition of the family unit. Analysis of the emotional state of employees in the context of security was studied in the works of Rudenko A.M. et al. [14] and Pishchik V. I. [15].

Family relationships have always been important in explaining the causes of various problems in law enforcement officers. Yu Helen H., studying female officers, concludes that most often the reason for leaving the service is a conflict between work and family. The author emphasizes that family-oriented public administration policies will help reduce staff turnover [16].

Foreign studies attach great importance to the study of the balance between work and family. For example, studies by Vieira et al., show that employees who are satisfied with the balance between work and family are more likely to feel physically and psychologically healthy and energetic. They are likely to be optimistic, mentally and emotionally stable, and will strive to develop a sense of self-efficiency [17]. Wayne J.H. et al., in a review study of the work-family balance problem, emphasizes that those who are satisfied with their workfamily balance can effectively allocate resources between work and family, while experiencing a sense of independence and a positive side effect [18]. Similar results were obtained by Heras, M. L., Rofcanin Y. et al. and expanded in connection with satisfaction with the balance of family-work-organizational culture-efficiency of public administration [19].

Arefin M. S. et al., studying the influence of organizational policy on satisfaction with the functioning of the family system by employees of the enterprise, found that organizational policy and satisfaction with the functioning of the family are negatively related. The authors note that managers should reduce the scope of organizational policies to avoid their impact on family members. In addition, the researchers found that social support from family members plays a crucial role in reducing the negative impact of organizational policies on 
family processes. Researchers believe that the adoption of personnel practices, such as training, expanding family-organization communication, can increase the ability of employees to cope with the negative consequences of organizational policies [20].

Russian psychology also examines the impact of professional activity on the family and household sphere, and vice versa, aspects of the impact of marital relations on professional activity [12, 21, 22, 23]. The authors of these studies have identified factors of "emotional burnout "of employees' wives, which is expressed by emotional coldness, spiritual alienation and restrained reactions. These include physical and nervous overloads of law enforcement officers, which are burdened by a lack of communication and monotony of family leisure. Based on the identified factors of imbalance in the family sphere, there is a need for serious psychological developments to address the issues of optimizing the psychological climate in the families of law enforcement officers. Morozova O. M., Troshina T. I. describe in the historical context the peculiarities of women's perception of work and professional activity of men in military service. The glorification of revolutionaries, soldiers, and defenders contributed to the departure of women from their families to the front [24]. This behavior caused children and other family members to suffer.

The use of forms and methods of interaction between the psychologist and the families of employees remains an unresolved issue. In our opinion, this area of work of psychologists of law enforcement agencies requires development and improvement. Special attention in this work should be paid to the psychological support of married couples, since the state of the family system at all levels (marital, child-parent, extended family), ultimately depends on the emotional climate in the couple.

For correct, competent and effective implementation of psychological work with the families of law enforcement officers, it is necessary to study the factors that affect the quality of psychological health in these families, one of the most important of which is the personal qualities of women who not only share life with their husbands, but also provide them with the necessary psychological support to cope with negative emotional states that arise as a result of the influence of the above factors, sometimes very extreme official activities.

\section{Materials and methods}

The empirical sample was made up of 205 women who are the spouses of law enforcement officers. To identify the personal characteristics of the respondents, the "Individualtypological questionnaire (ITQ) by L. N. Sobchik [25] and the "Questionnaire of the level of subjective control" (QSC), developed on the basis of the G. Rotter's scale worked out in Research Institute of Bechterev were used. To identify the components of the psychological climate in the families of law enforcement officers, the test "Analysis of family anxiety" (AFA) by E. G Eidemiller and V. Justitskis [27], the test "Understanding, emotional attraction, authority" (UEA) by A. N. Volkova [28] and the "Marriage satisfaction Questionnaire" (MSQ) developed by V. V. Stolin, T. A. Romanova and G. P. Butenko[29] were applied. Mathematical data processing was performed using linear regression analysis, which allows us to determine the degree and specifics of the influence of some indicators on others. Data processing was performed using standard computer programs for statistical analysis: Microsoft Office Excel and SPSS 20.0 for Windows-Statistical Package for the Social Science (statistical package for social Sciences).

The purpose of the work was to study the personal characteristics of the wives of employees of power structures as predictors of the formation of the psychological climate in the family system.

We tested the assumptions that the personal characteristics of employees ' wives can be predictors of the psychological climate in the family. 


\section{Results}

Table 1. Results of linear regression analysis.

\begin{tabular}{|c|c|c|c|}
\hline Dependent change & Influencing change & $\begin{array}{c}\text { connectio } \\
\mathbf{n}\end{array}$ & $\begin{array}{l}\text { meaning. } \\
\text { (p) }\end{array}$ \\
\hline \multirow{3}{*}{$\begin{array}{l}\text { Family wine (Family } \\
\text { Anxiety Analysis) }\end{array}$} & L (Individual typological questionnaire) & $-0.393 * *$ & 0.000 \\
\hline & Sn (Individual typological questionnaire) & $0.322 *$ & 0.019 \\
\hline & Lab (Individual typological questionnaire) & $-0.268^{*}$ & 0.015 \\
\hline \multirow{3}{*}{$\begin{array}{l}\text { Family anxiety (Family } \\
\text { Anxiety Analysis) }\end{array}$} & L (Individual typological questionnaire) & $-0.340 * *$ & 0.002 \\
\hline & Agr (Individual typological questionnaire & $0.253 *$ & 0.033 \\
\hline & $\mathrm{Rg}$ (Individual typological questionnaire) & $-0.372 * *$ & 0.008 \\
\hline \multirow{2}{*}{$\begin{array}{l}\text { Family tension (Family } \\
\text { Anxiety Analysis }\end{array}$} & Lab (Individual typological questionnaire) & $-0.206^{*}$ & 0.031 \\
\hline & Ii (Subjective control level) & $0.339 *$ & 0.024 \\
\hline \multirow{4}{*}{$\begin{array}{l}\text { General family anxiety } \\
\text { (Family Anxiety Analysis) }\end{array}$} & L (Individual typological questionnaire) & $-0.329 * *$ & 0.002 \\
\hline & $\mathrm{Rg}$ (Individual typological questionnaire) & $-0.302 *$ & 0.033 \\
\hline & Sn (Individual typological questionnaire) & $0.276^{*}$ & 0.048 \\
\hline & Lab (Individual typological questionnaire) & $-0.247^{*}$ & 0.027 \\
\hline \multirow{7}{*}{$\begin{array}{l}\text { Understanding } \\
\text { (Understanding. } \\
\text { emotional attraction. } \\
\text { authority) }\end{array}$} & Ext (Individual typological questionnaire) & $0.300 * *$ & 0.000 \\
\hline & Int (Individual typological questionnaire) & $-0.160 * *$ & 0.010 \\
\hline & Sp (Individual typological questionnaire) & $0.208^{*}$ & 0.013 \\
\hline & $\operatorname{Rg}$ (Individual typological questionnaire) & $0.475 * *$ & 0.000 \\
\hline & Lab (Individual typological questionnaire) & $0.133^{*}$ & 0.016 \\
\hline & Ig (Subjective control level) & $0.723 * *$ & 0.000 \\
\hline & Ii (Subjective control level) & $0.415 * *$ & 0.000 \\
\hline \multirow{4}{*}{$\begin{array}{ll}\text { Emotional attraction } \\
\text { (Understanding. } \\
\text { emotional attraction. } \\
\text { authority) }\end{array}$} & A (Individual typological questionnaire) & $-0.391 * *$ & 0.002 \\
\hline & Ext (Individual typological questionnaire) & $0.364 * *$ & 0.006 \\
\hline & $\mathrm{Rg}$ (Individual typological questionnaire) & $0.276^{*}$ & 0.019 \\
\hline & Ig (Subjective control level) & $0.744 * *$ & 0.006 \\
\hline \multirow{7}{*}{$\begin{array}{l}\text { Authority (Understanding. } \\
\text { emotional attraction. } \\
\text { authority) }\end{array}$} & A (Individual typological questionnaire) & $-0.696^{* *}$ & 0.000 \\
\hline & Ext (Individual typological questionnaire) & $0.344 * *$ & 0.005 \\
\hline & Agr (Individual typological questionnaire) & $-0.233^{*}$ & 0.013 \\
\hline & Ig (Subjective control level) & $0.613 *$ & 0.019 \\
\hline & If (Subjective control level) & $0.221 *$ & 0.045 \\
\hline & Ip (Subjective control level) & $-0.338^{*}$ & 0.028 \\
\hline & Ii (Subjective control level) & $0.274 *$ & 0.030 \\
\hline \multirow{9}{*}{$\begin{array}{l}\text { Marriage Satisfaction } \\
\text { (Overall satisfaction with } \\
\text { marriage) }\end{array}$} & A (Individual typological questionnaire) & $-0.415 * *$ & 0.000 \\
\hline & Agr (Individual typological questionnaire) & $-0.196^{* *}$ & 0.010 \\
\hline & $\operatorname{Rg}$ (Individual typological questionnaire) & $0.303 * *$ & 0.001 \\
\hline & Sn (Individual typological questionnaire) & $0.207^{*}$ & 0.020 \\
\hline & Lab (Individual typological questionnaire) & $0.162 *$ & 0.022 \\
\hline & Ig (Subjective control level) & $0.698 * *$ & 0.001 \\
\hline & Ip (Subjective control level) & $-0.310^{*}$ & 0.015 \\
\hline & Ii (Subjective control level) & $0.560 * *$ & 0.000 \\
\hline & Ih (Subjective control level) & $-0.352 * *$ & 0.000 \\
\hline
\end{tabular}

** - the relationship is significant at the level of $0.01{ }^{*}$ - the relationship is significant at the level of 0.05 .

At a high level of statistical significance direct impact of the indicator on the scale rigidity $(\mathrm{Rg})$ techniques "ITQ" on the degree of understanding of the spouse $(\mathrm{p}=0,000)$ and marital satisfaction $(p=0.001)$, and a few less expressed statistically significant influence of this indicator on the degree of emotional attraction to the partner by marriage $(p=0.019)$, there was a strong negative effect of this indicator on level of family anxiety $(p=0.008)$ and less pronounced negative influence on the integral indicator of the anxiety associated with family situation $(\mathrm{p}=0.033)$. 
At the average level of statistical significance, the direct influence of the indicator on the lability scale $(\mathrm{Lab})$ of the ITO method on the degree of understanding of the spouse $(\mathrm{p}=$ $0.016)$ and satisfaction with marriage $(\mathrm{p}=0.022)$, and its negative impact on overall family anxiety as an integral indicator of family distress $(p=0.027)$, and especially on its components such as family guilt $(\mathrm{p}=0.015)$ and family tension $(\mathrm{p}=0.031)$.

The integral indicator of the method "ITQ", reflected in the scale of total internality (TI), at a high level of statistical significance directly affect three components of the psychological climate of the family, such as understanding $(p=0,000)$, emotional attraction $(p=0.006)$ and the degree of marriage satisfaction $(\mathrm{p}=0.001)$, and also average statistical significance has a direct impact on the credibility factor $(\mathrm{p}=0.019)$.

The indicator on the internality scale in the field of interpersonal relations (IR) of the QSC method at a high level of statistical confidence affects two factors that regulate the atmosphere in the family, such as understanding $(\mathrm{p}=0.000)$ and the level of satisfaction with marriage $(p=0.000)$, and at an average level of statistical significance directly affects the level of authority $(\mathrm{p}=0.030)$ and family tension $(\mathrm{p}=0.024)$.

The indicator on the sensitivity scale (Sn) of the ITQ method at the average level of statistical confidence directly affects such factors of the family emotional atmosphere as the integral indicator of general family anxiety $(\mathrm{p}=0.048)$, especially such an aspect as family guilt $(\mathrm{p}=0.019)$, and has a direct impact on the overall level of satisfaction with marriage $(\mathrm{p}$ $=0.020)$.

The "ITQ" extraversion scale (Ext) indicator at a high level of statistical significance has a direct impact on such factors of the family psychological climate as understanding $(\mathrm{p}=$ $0.000)$, emotional attraction $(p=0.006)$ and authority $(p=0.005)$. The indicator on the spontaneity scale (Sp) of the ITQ method also affects the factor of family understanding at a high level of statistical significance $(p=0.005)$, and the indicator on the internality scale in the field of failures (In) of the QSC method at an average level of statistical significance directly affects the factor of authority $(p=0.045)$. The indicator on the introversion scale (Int) of the "ITQ" method, which characterizes self-absorption and a tendency to limit contacts with the outside world and other people, at a high level of statistical significance negatively affects the understanding factor $(p=0.010)$.

The indicator on the lie scale (L) of the "ITQ" method affects 3 factors that determine the emotional atmosphere in the family. The desire of women to show themselves in the best light at a high level of statistical confidence inversely affects the integral indicator of their overall family anxiety $(p=0.002)$, in particular - on such factors as family guilt $(p=0.000)$ and family anxiety $(\mathrm{p}=0.002)$.

Indicator on a scale of internality in the field of industrial relations at the middle level of statistical confidence feeds back the level of credibility for the respondents opinions of the partner $(p=0.028)$ and negatively affects marriage satisfaction $(p=0.015)$, as an indicator on a scale of internality in the area of health $(\mathrm{IH})$ techniques of QSC, at a high level of statistical significance adversely affect the degree of marriage satisfaction $(p=0,000)$.

Indicator on a scale of aggressiveness (Agr) techniques of "ITQ" at the middle level of statistical significance has a direct impact on the family factor of anxiety $(p=0.033)$ and inverse impact on the factor of credibility $(p=0,013)$, at a high level of statistical significance is negatively affecting the degree of satisfaction with marriage $(p=0,010)$, as an indicator on a scale of aggravatio (A) of the policy "ITO" at a high level of statistical significance adversely affecting such components of the emotional atmosphere of the family as the emotional attraction $(p=0.002)$, authority $(p=0.000)$ and marriage satisfaction $(p=0.000)$. 


\section{Discussion}

To maintain an optimal psychological climate in the family, it is necessary to demonstrate both rigidity in terms of emotional stability and a clear definition of values, and lability, which manifests itself as a willingness and ability to feel the state of the partner and empathically engage in interaction with him on his "wave". This combination of influencing factors has a positive effect on mutual understanding in the family and the level of satisfaction with marriage, as well as reduces the likelihood of negative emotional states such as guilt, feelings of helplessness and increased anxiety. Studying the typology of the family and the features of its functioning, Everri M. et al., found that rigidity manifests itself as an adaptive ability in families of such types as "rigidly balanced" and "flexibly fluctuating". In these types of families, rigidity is associated with positive aspects of family functioning, such as flexibility, cohesion, parental control, and a high level of family satisfaction [30].

It was also found that the ability of respondents to recognize and accept their responsibility in various spheres of life and particularly in the sphere of interpersonal relationships has a direct impact on the degree of marriage satisfaction, level of understanding of the partner, an emotional connection with the partner, and the willingness to listen to his ther opinion as authoritative, and also provides a responsible attitude to their family responsibilities, even those that seem intractable. This is confirmed by research by O'Neal C. W. et al., who studying families of military and civil servants came to the conclusion that families with shared responsibility and collective competence have a higher level of wellbeing, that is, the level of anxiety is low and depressive symptoms are practically absent, but high self-efficacy and life satisfaction are noted [31].

The ability to reflect and predict the consequences of their own actions determines the responsible attitude of respondents to their behavior in the family and avoid committing actions that negatively affect the family emotional atmosphere, and the ability to recognize their responsibility for failures allows respondents to accept the partner's opinion as authoritative and listen to it.

Openness, sociability, outwardness and a tendency to expand contacts with the world, naturalness and spontaneity in communication facilitate the process of interaction in the family, ensuring that the spouses understand each other, recognizing the authority of the partner and contributing to an increase in the degree of emotional intimacy.

The article by Aloia Lindsey S. reveals similar results of studying the communicative function of the family, orientations to certain ways of maintaining relationships and satisfaction with child-parent relationships. The results showed that orientation to verbal communication in the family and the implementation of behavior aimed at maintaining relationships are positively associated with relationship satisfaction; orientation to the external compliance of the family with accepted social norms was not associated with relationship satisfaction. In addition, the data obtained indicate the effectiveness of a model in which positivity and openness mediate the relationship between orientation to family communication and children's satisfaction with child-parent relationships in the family [32].

The desire to appear better helps to minimize the respondents ' inadequate sense of responsibility for all the negative things that happen in their families, the feeling of lack of control of the situation in the family and their own inability to make the necessary changes in family relations, in their opinion.

Factors that negatively affect the socio-psychological climate in the family can be called excessive involvement of respondents in production processes, contributing to some disconnection from the control of processes occurring in the family, excessive concern for their own health, leading to hypochondria, the desire to emphasize the problems and difficulties of their own character, stubbornness and contrariness in defending their interests. These results are consistent with Bowen P. et al., who found that conflict between work and 
family causes psychological distress, sleep disorders, psychological disorders, decreased emotional background and sociability. The authors note that stress received at work plays a key role, directly or indirectly, in the deterioration of the psychological atmosphere in the families of employees [33].

Thus, we see that the specifics of the psychological climate in the families of law enforcement officers depend on the personal qualities of the members of these families, in particular, on the personal qualities of the wives of employees. At the same time, we can assume that the psychological climate in the family is affected by the peculiarities of the partner's official activities.

\section{Conclusions}

The results of the study of the personal characteristics of the wives of law enforcement officers as predictors of the formation of the psychological climate in the family system allowed us to draw the following conclusions.

Such a personal quality as the partner's rigidity is a predictor of the degree of understanding of the spouse, satisfaction with the marriage, emotional attraction to the partner in marriage, the level of family anxiety and an integral indicator of anxiety related to the family situation. The lability of the wife of a law enforcement officer determines in the family system the degree of understanding of the spouse, satisfaction with the marriage, general family anxiety and family problems (family guilt and family tension). The internal locus of control is a determinant of such components of the psychological climate of the family as understanding, emotional attraction, the degree of satisfaction with the marriage, the authority of the partner's opinion, and family tension. Such a personal quality as sensitivity is crucial in the manifestation of family anxiety (family guilt) and satisfaction with marriage. Such factors of the psychological climate in the family as understanding, emotional attraction and authority are determined by the manifestation of extroversion in the spouse. The spontaneity of the spouse affects mutual understanding in the family and with an increase in her aggressiveness, an increase in general family anxiety is predicted, a decrease in the partner's authority and the degree of satisfaction with the marriage. The rate of aggravatio negatively influences the emotional atmosphere of the family (the emotional attraction, credibility, and marital satisfaction).

Prospects of the research are aimed at studying the content characteristics of personal peculiarities of partners in the family system, factors that determine satisfaction with marriage and the degree of influence of the psychological climate of the family on the professional effectiveness and success of an employee of law enforcement agencies.

\section{References}

1. I.T. Adams, S.H. Mastracci, Policing-An International Journal Of Police Strategies \& Management 2(43), 314-329 (2020) DOI: 10.1108/PIJPSM-06-2019-0094

2. G.V. Talalaeva, V.S. Koshkarov, Sibirskiy Psikhologicheskiy Zhurnal-Siberian Journal Of Psychology 59, 149-171 (2016) DOI: 10.17223/17267080/59/10

3. R. Ramchand, J. Saunders, K.C. Osilla, P. Ebener, V. Kotzias, E. Thornton, L. Strang, M. Cahill, Journal Of Police And Criminal Psychology 1(34), 55-66 (2019) DOI: 10.1007/s11896-018-9269-x

4. A. Miller, L. Unruh, International Journal Of Emergency Services 3(8), 221-235 (2019) DOI: 10.1108/IJES-01-2018-0006 
5. M.R. Butt, A. Mahmood, S. Kanwal, F.A. Bajwa, Middle East Journal Of Management 2(6), 170-185 (2019) DOI: 10.1504/MEJM.2019.097815

6. V.I. Rodionova, L.A. Shvachkina, P.A. Ponomaryov, K.V. Vodenko, Contributions To Economics, 417-422 (2017)

7. S.E. Wolfe, E. Scott, J. Rojek, V.M. Manjarrez, A. Rojek, Journal Of Criminal Justice 54, 20-29 (2018) DOI: 10.1016/j.jcrimjus.2017.11.003

8. A.M. Schuck, C.E. Rabe-Hemp, Policing-An International Journal Of Police Strategies \& Management 1(41), 113-128 (2018) DOI: 10.1108/PIJPSM-09-2016-0137

9. M.V. Vinogradov, O.A. Ulyanina, Psychology And Law 3(9), 245-260 (2019) DOI: 10.17759/psylaw.2019090318

10. V.L. Kubyshko, V.M. Kruk, I.N. Noss, T.I. Borodina, Psychology And Law 3(8), 34-47 (2018) DOI: 10.17759/psylaw.2018080303

11. N.V. Serdyuk, Y.G. Naumov, L.L. Grishchenko, Psikhologicheskaya Nauka I Obrazovanie-Psychological Science and Education 5(22), 85-93 (2017) DOI: 10.17759/pse.2017220510

12. N.I. Martyshova, Materials of the international correspondence scientific-practical conference "Personality, family, society: issues of modern psychology" (ENSKE, Novosibirsk, 2011)

13. T. Burch, Journal Of Business And Psychology 5(35), 593-607 (2020) DOI: 10.1007/s10869-019-09641-y

14. A.M. Rudenko, V.I. Rodionova, V.N. Stepanova, Advances In Intelligent Systems And Computing 726, 1144-1155 (2019) DOI: 10.1007/978-3-319-90835-9_129

15. V.I. Pishchik, Social Psychology and Society 2(10), 67-81 (2019) DOI: 10.17759/sps.2019100206

16. H.H. Yu, International Journal of Public Administration 4(42), 345-357 (2019). DOI: $10.1080 / 01900692.2018 .1463541$

17. J.M. Vieira, M. Matias, F.G. Lopez, P.M. Matos, Journal of Vocational Behavior 1(109), 152-165 (2018). DOI: 10.1016/j. jvb.2018.10.007

18. J.H. Wayne, M.M. Butts, W.J. Casper, T.D. Allen, Personnel Psychology 1(70), 167210 (2017) https://doi.org/10.1111/peps.12132

19. M.L. Heras, Y. Rofcanin, P.I. Escribano, S. Kim, M.C.J. Mayer, Human Resource Management Journal (2020) DOI: 10.1111/1748-8583.12317

20. M.S. Arefin, M.S. Alam, S.L. Li, L.R. Long, Personnel Review (2020) DOI: 10.1108/PR-02-2020-0107

21. L.A. Dmitrieva, Socio-psychological characteristics of the mutual influence of professional activity and family relations of employees of the internal affairs bodies and the penal system (Acad. ex. Ministry of Internal Affairs of the Russian Federation, Moscow, 2002) https://search.rsl.ru/ru/record/01002314250

22. I.O. Kotenev, L.A. Dmitrieva, Vedomosti UIS 5, 38-41 (2005) http://lawlibrary.ru/article1188109.html

23. O.N. Kolosnitsyna, Psychopedagogy in law enforcement 3(30), 50-54 (2007) https://pp.omamvd.ru/wp-content/uploads/2017/11/Psih-2007-№3-30.pdf

24. O.M. Morozova, T.I. Troshina, Contemporary history of Russia 2(16), 8-30 (2016) DOI: 10.21638/11701/spbu24.2016.201

25. L.N. Sobchik, Personnel management and psychodiagnostics: a practical guide (Moscow, LLC "Company Borges", 2010) https://search.rsl.ru/ru/record/01004935466 
26. E.B. Fantalova, Psychodiagnostics: a methodological guide for the organization of independent work of full-time students (MGPPU, Moscow, 2008) https://dib.rsl.ru/viewer/01004657932\#?page=1

27. E.G. Eidemiller, Family diagnosis and family psychotherapy (St. Petersburg, Speech, 2007)

28. A.N. Volkova, T.M. Trapeznikova, Questions of psychology 5, 110-117 (1985) http://www.voppsy.ru/issues/1985/855/855110.htm

29. Psychological tests. Humanig (VLADOS, Moscow, 2003)

30. M. Everri, T. Mancini, L. Fruggeri, Journal of Child And Family Studies 10(25), 29872997 (2016) DOI: 10.1007/s10826-016-0460-3

31. C.W. O'Neal, J.A. Mancini, G.L. Bowen, Journal of Community Psychology 5(48), 1637-1650 (2020) DOI: 10.1002/jcop.22357

32. L.S. Aloia, Family Journal 1(28), 83-89 (2020) DOI: 10.1177/1066480719896561

33. P. Bowen, R. Govender, P. Edwards, K. Cattell, Construction Management And Economics 3(36), 153-174 (2018) DOI: 10.1080/01446193.2017.1341638 